MEDIKA ALKHAIRAAT : JURNAL PENELITIAN KEDOKTERAN DAN KESEHATAN 1(2): 57-63

e-ISSN: 2656-7822, p-ISSN: 2657-179X

\title{
GAMBARAN KLINIS PENDERITA DISPEPSIA YANG BEROBAT DI BAGIAN PENYAKIT DALAM RSU ANUTAPURA PALU TAHUN 2018
}

\author{
Deasy Handayani Nento ${ }^{1}$, Ruslan Ramlan Ramli ${ }^{1 *}$, Maria Rosa Da Lima ${ }^{1}$ \\ ${ }^{1}$ Program Studi Pendidikan Dokter, Fakultas Kedokteran Universitas Alkhairat, Jl. Diponegoro No. 39 Palu \\ 94221, Sulawesi Tengah, Indonesia \\ *Corresponding author: Telp: +6282225257575, email: ramlanruslan@gmail.com
}

\begin{abstract}
ABSTRAK
Dispepsia adalah sindrom yang ditandai dengan gangguan anatomi atau fungsional dari saluran pencernaan, dan didefinisikan sebagai rasa nyeri atau tidak nyaman yang terutama dirasakan di daerah perut bagian atas. Faktor resiko dispepsia beragam mulai dari makanan dan lingkungan, sekresi cairan lambung, persepsi viseral lambung, NSAIDs (Non-Stereoidal Antiinflamatory Drugs), dan infeksi Helicobacter pylori. Selain itu, faktor gaya hidup dan konsumsi alkohol juga ikut mempengaruhi timbulnya gejala dispepsia. Tujuan penelitian adalah untuk mengetahui distribusi gambaran klinis penderita dispepsia yang berobat di Bagian Penyakit Dalam RSU Anutapura Palu tahun 2018. Metoda yang digunakan adalah metode penelitian deskriptif pada 95 responden penderita Dispepsia yang berobat di Bagian Penyakit Dalam RSU Anutapura Palu tahun 2018, untuk mengetahui distribusi gambaran klinis penderita. Pengumpulan data melalui observasi berupa mual, muntah, cepat kenyang, sering bersendawa, dan perut kembung dengan cara wawancara. Pengolahan data menggunakan SPSS 21 untuk menghitung distribusi frekuensi masing-masing variabel. Hasil penelitian menunjukkan bahwa distribusi gambaran klinis penderita dispepsia di RSU Anutapura tahun 2018 adalah sebagai berikut (1) Paling sering muncul kombinasi 3 gejala yaitu 35 responden (36,84\%); (2) kombinasi 4 gejala yaitu 25 responden (26,31\%); (3) kombinasi 5 gejala yaitu 17 responden $(17,89 \%)$; (4) kombinasi 2 gejala yaitu 13 responden $(13,70 \%)$; (5) dan yang paling sedikit kombinasi 1 gejala yaitu 5 responden $(5,26 \%)$. Disimpulkan bahwa penderita Dispepsia yang berobat di Bagian Penyakit Dalam RSU Anutapura Palu ditemukan gejala berupa mual, muntah, cepat kenyang, sedawa, kembung. Yang paling banyak didapatkan yaitu cepat kenyang dan kembung. Pasien paling sering datang dengan 3 kombinasi gejala.
\end{abstract}

Kata Kunci: Dispepsia, gambaran klinis, penyakit dalam

\section{ABSTRACT}

Dyspepsia is a syndrome characterized by anatomic or functional disorders of the digestive tract, pain and discomfort that is mainly felt in the upper abdomen area. Risk factors for dyspepsia range from food and the environment, gastric fluid secretion, gastric visceral perception, NSAIDs (NonStereoidal Antiinflamatory Drugs), and Helicobacter pylori infection. In addition, lifestyle factors and alcohol consumption also influence the appearance of symptoms of dyspepsia. The purpose of this research was to determine the distribution of the clinical feature of dyspepsia patients who were treated at Internal Section of Anutapura Hospital, Palu in 2018. The study used descriptive methods on 95 respondents with dyspepsia who were treated at Internal Section of Anutapura Hospital, Palu in 2018, to determine the distribution of patient clinical image. Data collection through observation in the form of nausea, vomiting, fast satiety, often belching, and flatulence by interview. Data processing uses SPSS 21 to calculate the frequency distribution of each variable. The results showed that clinical image distribution of dyspepsia patients in Anutapura Hospital as follows (1) The most frequent combination of 3 symptoms was 35 respondents (36.84\%); (2) a combination of 4 symptoms, 25 respondents (26.31\%); (3) a combination of 5 symptoms namely 17 respondents 
MEDIKA ALKHAIRAAT : JURNAL PENELITIAN KEDOKTERAN DAN KESEHATAN 1(2): 57-63

e-ISSN: 2656-7822, p-ISSN: 2657-179X

(17.89\%); (4) a combination of 2 symptoms namely 13 respondents (13.70\%); (5) and the least combination of 1 symptom is 5 respondents (5.26\%). It was concluded that dyspepsia patients were treated at Internal Section of Anutapura Hospital Palu were found symptoms of nausea, vomiting, satiety, belching, bloating. The most widely obtained is satiety and bloated. Patients most often present with 3 combinations of symptoms.

Keywords: Dyspepsia, clinical features, internal disease

\section{PENDAHULUAN}

Dispepsia menurut American Society For Gastrointestinal Endoscopy adalah sindrom yang ditandai dengan gangguan anatomi atau fungsional dari saluran pencernaan, dan didefinisikan sebagai rasa nyeri atau tidak nyaman yang terutama dirasakan di daerah perut bagian atas. Sedangkan menurut Kriteria Roma III terbaru, dispepsia fungsional didefinisikan sebagai sindrom yang mencakup satu atau lebih dari gejala-gejala berikut: perasaan perut penuh setelah makan, cepat kenyang, sendawa, dengan atau tanpa kembung, mual dan muntah. $1,2,3,4$

Angka kejadian dispepsia di dunia seperti di Negara Singapura tahun 2012 sebanyak 7-8\% kasus, di Negara Skandinavia tahun 2012 sebanyak 20,40\% kasus dan di Spanyol sebanyak 23\% kasus. Untuk wilayah Amerika Serikat tahun 2013 sebanyak 23\%-25,8\% kasus dispepsia. India tahun 2012 sebanyak 30,4\% kasus, di negara Inggris pada tahun 2014 sebanyak 38,2\%-41\% kasus. Negara Nigeria merupakan negara dengan angka kejadian terbanyak tahun 2012 sebanyak $45 \%$ kasus. ${ }^{5,6,7}$

Angka kejadian di indonesia seperti di Makassar tahun 2011 sebanyak 55\% kasus dispepsia. Solo tahun 2008 sebanyak 51,8\% kasus. Yogyakarta sebanyak 30,6\% kasus, Surabaya sebanyak 23,5\% kasus dan di Jakarta merupakan kasus terendah tahun 2010 sebanyak $8 \%$ kasus dispepsia. ${ }^{8,9,10}$

Berdasarkan data yang didapatkan dari RSU Anutapura Palu jumlah pasien dispepsia yang datang berobat pada tahun 2015 sebanyak 2.854 kasus, pada tahun 2016 sebanyak 3.697 kasus, dan pada tahun 2017 pasien dispepsia yang datang berobat sebanyak 2.011 kasus.

Dari data tersebut dapat disimpulkan bahwa angka kejadian dispepsia di RSU Anutapura
Palu didapatkan bahwa pada tahun 2016 mengalami peningkatan, tetapi pada tahun 2017 mengalami penurunan.

Faktor resiko dispepsia beragam mulai dari makanan dan lingkungan, sekresi cairan lambung, persepsi viseral lambung, NSAIDs (Non-Stereoidal Antiinflamatory Drugs), dan infeksi Helicobacter pylori. Selain itu, faktor gaya hidup dan konsumsi alkohol juga ikut mempengaruhi timbulnya gejala dispepsia. Diduga faktor psikis juga berpotensi memicu munculnya gangguan fungsional pada lambung dan usus. ${ }^{5,11}$

Dampak dari dispepsia umumnya dapat menggangu produktifitas dan aktivitas seharihari, apabila asam lambung yang meningkat secara terus menerus, hal ini akan menyebabkan kerusakan pada lambung, yang bila perlangsungannya lama akan mengakibatkan ulkus pada lambung yang lebih fatal lagi dapat mengakibatkan kematian apabila tidak diobati. 5,11

\section{METODOLOGI}

Penelitian ini menggunakan metode penelitian Deskriptif dengan pendekatan potong lintang (cross sectional). Penelitian dilakukan di bagian Penyakit Dalam Rumah sakit umum Anutapura Palu pada 16 April - 16 Juni 2018. Populasi Penelitian seluruh penderita dispepsia yang berobat di RSU Anutapura pada tahun 2018, dan subyek Penelitian adalah Seluruh penderita dispepsia yang berobat di Bagian Penyakit Dalam Rumah sakit umum Anutapura pada tahun 2018 dan sesuai dengan kriteria penelitian. Penelitian ini bersifat deskriptif kategorik, maka besar sampel dapat ditentukan dengan menggunakan rumus Teknik Slovin:

$$
n=\frac{\mathrm{N}}{1+\mathrm{N}(\mathrm{e})^{2}}
$$


Keterangan :

$\mathrm{n} \quad=$ jumlah sampel

$\mathrm{N} \quad=$ jumlah populasi

e = batas toleransi kesalahan (error tolerance)

$$
\begin{gathered}
n=\frac{2.011}{1+2.011(0,1)^{2}} \\
n=\frac{2.011}{1+2.011(0,01)} \\
n=\frac{2.011}{21,11} \\
n=95 \text { orang }
\end{gathered}
$$

\section{Cara Pengambilan Sampel}

Teknik pengambilan sampel yang digunakan dalam penelitian ini adalah NonProbability Sampling, Yaitu Consecutive Sampling dengan mengambil semua penderita yang didiagnosa oleh dokter di Bagian Penyakit Dalam RSU Anutapura menderita dispepsia yang memenuhi kriteria penelitian diikutkan dalam penelitian sampai jumlah subyek terpenuhi.

\section{Prosedur Penelitian}

1. Populasi yang telah diteliti adalah semua pasien sakit perut yang di diagnosis oleh dokter Ahli Penyakit Dalam sebagai dispepsia yang berobat di Bagian Penyakit Dalam RSU Anutapura.

2. Penjelasan kepada subyek penelitian :

a). Peneliti telah memberikan penjelasan kepada subyek penelitian latar belakang, tujuan, dan manfaat dari penelitian. Serta diberi penjelasan mengenai perlakuan terhadap subyek selama penelitian dan jaminan kerahasiaan data serta jaminan keselamatan selama tindakan penelitian.

a) Telah dijelaskan juga tentang hak-hak dari subyek, yaitu hak menolak dan mengundurkan diri dari penelitian tanpa konsekuensi kehilangan hak mendapat pelayanan kesehatan yang diperlukannya, hak untuk bertanya dan mendapat penjelasan kesehatan yang diperlukannya, hak untuk bertanya dan mendapat penjelasan bila masih diperlukan. Subyek juga diberitahu bahwa semua biaya yang dibutuhkan dalam penelitian ini akan ditanggung oleh peneliti.

3. Setelah subyek mengerti dengan semua penjelasan, peneliti telah meminta persetujuan dari pasien untuk ikut serta menjadi subyek penelitian dengan menandatangani formulir persetujuan.

4. Subyek penelitian yang memenuhi kriteria inklusi dan tidak memiliki kriteria eksklusi telah diikutkan dalam penelitian tanpa paksaan dan bersifat suka rela.

5. Selanjutnya peneliti telah melakukan pengambilan data dengan metode wawancara sesuai dengan pertanyaan pertanyaan yang ada pada kuesioner dan diisi sesuai dengan jawaban dari pasien.

6. Kemudian dilakukan pengisian food recall untuk mengetahui makanan apa saja yang telah pasien konsumsi.

7. Semua data yang telah terkumpul telah di input ke dalam komputer selanjutnya telah dilakukan pengolahan dan analisis data lebih lanjut dengan menggunakan program SPSS.

8. Setelah analisis data selesai, peneliti mempersiapkan untuk melakukan penulisan hasil untuk selanjutnya diseminarkan pada penyajian hasil.

\section{Instrument Penelitian}

Instrumen yang digunakan untuk mengumpulkan data primer berupa data dari kuesioner pada penderita dispepsia yang berobat di Bagian Penyakit Dalam Rumah Sakit Umum Anutapura Palu tahun 2018

\section{Rencana Pengolahan Data}

Data pada penelitian ini diolah menggunakan perangkat lunak komputer program SPSS 20. Masalah deskripif kategorik dianalisis secara deskriptif untuk variabel kategorik. Hasilnya adalah berupa frekuensi dan presentase (proporsi) yang dapat disajikan dalam bentuk tabel maupun grafik. Pada penelitian deskriptif kategorik, hasil yang diharapkan adalah proporsi dan IK (Interval Kepercayaan) dari proporsi tersebut. Proporsi adalah perbandingan 
MEDIKA ALKHAIRAAT : JURNAL PENELITIAN KEDOKTERAN DAN KESEHATAN 1(2): 57-63

e-ISSN: 2656-7822, p-ISSN: 2657-179X

antara subjek yang mengalami efek yang dilihat dibanding terhadap keseluruhan subjek.

\section{HASIL DAN PEMBAHASAN}

HASIL

Penelitian ini dilakukan di Rumah Sakit Umum Anutapura Palu pada 16 April 2018 sampai dengan 16 Juni 2018. Subyek pada penelitian ini diambil dari penderita dispepsia yang rawat jalan dan rawat inap di Bagian Penyakit Dalam RSU Anutapura Palu selama kurun waktu penelitian berlangsung yang memenuhi kriteria subjek penelitian. Data yang diperoleh antara lain mual, muntah, cepat kenyang, sendawa, perut kembung pada pasien dispepsia. Hasil analisa statistik ditampilkan dengan sistematika sebagai berikut :

\section{a. Gambaran klinis mual}

Gambaran klinis dispepsia berdasarkan keluhan mual dapat dilihat pada tabel 1 berikut ini:

Tabel 1. Distribusi gambaran klinis mual pasien dyspepsia.

\begin{tabular}{ccc}
\hline Mual & $\mathrm{N}$ & $\%$ \\
\hline Ya & 71 & 74,7 \\
Tidak & 24 & 25,3 \\
Total & 95 & 100 \\
\hline
\end{tabular}

Berdasarkan tabel diatas, hasil dari 95 pasien dispepsia yang berobat jalan dan rawat inap di Bagian Penyakit Dalam RSU Anutapura dan memenuhi kriteria penelitian adalah sebanyak 71 responden $(74,7 \%)$ yang mengalami keluhan mual, dan 24 responden $(25,3 \%)$ tidak mengalami keluhan mual.

\section{b. Gambaran klinis muntah}

Gambaran klinis dispepsia berdasarkan keluhan muntah dapat dilihat pada tabel 2 berikut ini:

Tabel 2. Distribusi gambaran klinis muntah pasien dispepsia

\begin{tabular}{ccc}
\hline Muntah & $\mathrm{N}$ & $\%$ \\
\hline Ya & 41 & 43,2 \\
Tidak & 54 & 56,8 \\
Total & 95 & 100 \\
\hline
\end{tabular}

Berdasarkan tabel diatas, hasil dari 95 pasien dispepsia yang berobat jalan dan rawat inap di Bagian Penyakit Dalam RSU Anutapura dan memenuhi kriteria penelitian adalah sebanyak 41 responden $(43,2 \%)$ yang mengalami keluhan muntah, dan 54 responden $(56,8 \%)$ tidak mengalami keluhan muntah.

\section{c. Gambaran klinis cepat kenyang}

Gambaran klinis dispepsia berdasarkan keluhan mual dapat dilihat pada tabel 3 berikut ini:

Tabel 3. Distribusi gambaran klinis cepat kenyang pasien dispepsia

\begin{tabular}{ccc}
\hline $\begin{array}{c}\text { Cepat } \\
\text { Kenyang }\end{array}$ & $\mathrm{N}$ & $\%$ \\
\hline Ya & 75 & 78,9 \\
Tidak & 20 & 21,1 \\
Total & 95 & 100 \\
\hline
\end{tabular}

Berdasarkan tabel diatas, hasil dari 95 pasien dispepsia yang berobat jalan dan rawat inap di Bagian Penyakit Dalam RSU Anutapura dan memenuhi kriteria penelitian adalah sebanyak 75 responden $(78,9 \%)$ yang mengalami keluhan cepat kenyang, dan 20 responden $(21,1 \%)$ tidak mengalami keluhan cepat kenyang.

\section{d. Gambaran klinis sendawa}

Gambaran klinis dispepsia berdasarkan keluhan sendawa dapat dilihat pada tabel 4 berikut ini:

Tabel 4. Distribusi gambaran klinis sendawa pasien dispepsia

\begin{tabular}{ccc}
\hline Sendawa & $\mathrm{N}$ & $\%$ \\
\hline Ya & 58 & 61,1 \\
Tidak & 37 & 38,9 \\
Total & 95 & 100 \\
\hline
\end{tabular}

Berdasarkan tabel diatas, hasil dari 95 pasien dispepsia yang berobat jalan dan rawat inap di Bagian Penyakit Dalam RSU Anutapura dan memenuhi kriteria penelitian adalah sebanyak 58 responden $(61,1 \%)$ yang mengalami keluhan sendawa, dan 37 responden $(38,9 \%)$ tidak mengalami keluhan sendawa. 
MEDIKA ALKHAIRAAT : JURNAL PENELITIAN KEDOKTERAN DAN KESEHATAN 1(2): 57-63

e-ISSN: 2656-7822, p-ISSN: 2657-179X

e. Gambaran klinis perut kembung

Gambaran klinis dispepsia berdasarkan keluhan perut kembung dapat dilihat pada tabel 5 berikut ini:

Tabel 5. Distribusi gambaran klinis perut kembung pasien dispepsia

\begin{tabular}{ccc}
$\begin{array}{c}\text { Perut } \\
\text { Kembung }\end{array}$ & $\mathrm{N}$ & $\%$ \\
\hline Ya & 75 & 78,9 \\
Tidak & 20 & 21,1 \\
Total & 95 & $100 \%$ \\
\hline
\end{tabular}

Berdasarkan tabel diatas, hasil dari 95 pasien dispepsia yang berobat jalan dan rawat inap di Bagian Penyakit Dalam RSU Anutapura dan memenuhi kriteria penelitian adalah sebanyak 75 responden $(78,9 \%)$ yang mengalami keluhan perut kembung, dan 20 responden $(21,1 \%)$ tidak mengalami keluhan perut kembung.

Tabel 6. Distribusi kombinasi gejala dispepsia

\begin{tabular}{|c|c|c|c|c|}
\hline $\begin{array}{l}\text { Jumlah } \\
\text { gambaran } \\
\text { klinis }\end{array}$ & Gambaran klinis & $\mathrm{N}$ & $\%$ & $\begin{array}{l}\text { Tot } \\
\text { al } \\
\mathrm{N}\end{array}$ \\
\hline \multirow{3}{*}{1} & $\mathrm{M}$ & 2 & \multirow{3}{*}{$5,26 \%$} & \multirow{3}{*}{5} \\
\hline & $\mathrm{CK}$ & 2 & & \\
\hline & K & 1 & & \\
\hline \multirow{7}{*}{2} & $\mathrm{~S}+\mathrm{K}$ & 2 & \multirow{7}{*}{$13,70 \%$} & \multirow{7}{*}{13} \\
\hline & $M+S$ & 2 & & \\
\hline & $\mathrm{M}+\mathrm{CK}$ & 1 & & \\
\hline & $\mathrm{CK}+\mathrm{K}$ & 4 & & \\
\hline & $M+K$ & 1 & & \\
\hline & $\mathrm{M}+\mathrm{MN}$ & 1 & & \\
\hline & $\mathrm{CK}+\mathrm{S}$ & 2 & & \\
\hline \multirow{7}{*}{3} & $M+S+K$ & 6 & \multirow{7}{*}{$36,84 \%$} & \multirow{7}{*}{35} \\
\hline & $\mathrm{M}+\mathrm{MN}+\mathrm{K}$ & 3 & & \\
\hline & $\mathrm{M}+\mathrm{MN}+\mathrm{CK}$ & 6 & & \\
\hline & $\mathrm{CK}+\mathrm{S}+\mathrm{K}$ & 10 & & \\
\hline & $\mathrm{M}+\mathrm{CK}+\mathrm{K}$ & 8 & & \\
\hline & $\mathrm{M}+\mathrm{MN}+\mathrm{K}$ & 1 & & \\
\hline & $\mathrm{M}+\mathrm{CK}+\mathrm{S}$ & 1 & & \\
\hline \multirow{4}{*}{4} & $M+C K+S+K$ & 12 & \multirow{4}{*}{$26,31 \%$} & \multirow{4}{*}{25} \\
\hline & $\mathrm{M}+\mathrm{M}+\mathrm{CK}+\mathrm{S}$ & 4 & & \\
\hline & $\mathrm{M}+\mathrm{MN}+\mathrm{CK}+\mathrm{K}$ & 7 & & \\
\hline & $\mathrm{M}+\mathrm{MN}+\mathrm{S}+\mathrm{K}$ & 2 & & \\
\hline \multirow[t]{2}{*}{5} & $\begin{array}{l}\mathrm{M}+\mathrm{MN}+\mathrm{CK}+ \\
\mathrm{S}+\mathrm{K}\end{array}$ & 17 & 17,89 & 17 \\
\hline & & 95 & $100 \%$ & 95 \\
\hline
\end{tabular}


MEDIKA ALKHAIRAAT : JURNAL PENELITIAN KEDOKTERAN DAN KESEHATAN 1(2): 57-63

e-ISSN: 2656-7822, p-ISSN: 2657-179X

\section{Gambaran klinis muntah}

Dari hasil penelitian menurut gambaran klinis penderita dispepsia keluhan utama yang paling sedikit dikeluhkan pasien yang datang ke rumah sakit adalah muntah, dengan total sebanyak 41 responden $(43,2 \%)$. Hal ini sesuai dengan penelitian yang dilakukan oleh Citra dkk tahun 2016 yaitu dari 54 responden terdapat 20 orang $(37,04 \%)$ yang mengalami muntah.

Muntah terjadi karena lambung memberikan respon sinyal ke zona kemoreseptor oleh sistem saraf aferen dan saraf simpatis sehingga menyebabkan kontraksi antiperistaltik dan menyebabkan makanan kembali ke duodenum dan lambung setelah masuk ke usus. Karena banyaknya makanan yang terkumpul di lambung dan mengganggu kerja lambung dan duodenum sehingga duodenum teregang, akibatnya terjadi kontraksi kuat diafragma dan otot dinding abdominal sehingga menyebabkan tekanan di dalam lambung meningkat diikuti dengan pengeluaran isi lambung. ${ }^{12,13}$

\section{Gambaran klinis cepat kenyang}

Dari hasil penelitian gambaran klinis penderita dispepsia yang datang ke rumah sakit dengan keluhan cepat kenyang, total sebanyak 75 responden $(78,9 \%)$ dengan hasil presentasi terbanyak. Hal ini sesuai dengan penelitian yang dilakukan oleh Rizky dkk tahun 2015 yaitu dari 77 responden ada 38 orang $(49,4 \%)$ yang mengalami keluhan cepat kenyang.

Pada pasien yang mengalami perasaan cepat kenyang, selalu merasa perut penuh sehingga tidak dapat menghabiskan porsi makan biasa, ini terjadi karena adanya keterlambatan pengosongan lambung. ${ }^{14}$

\section{Gambaran klinis sendawa}

Dari hasil penelitian gambaran klinis penderita dispepsia yang datang ke rumah sakit dengan keluhan sering bersendawa, didapatkan sebanyak 58 responden $(61,1)$ yang mengalami keluhan sering bersendawa. Hal ini sesuai dengan penelitian yang dilakukan oleh Dewi pada tahun 2017 yaitu dari 65 responden ada 40 pasien $(61,53 \%)$ yang mengalami keluhan sering bersendawa.

Sendawa terjadi pada saat gas dalam perut menumpuk dan akan terjadi penggelembungan perut. Tekanan dalam perut meningkat lebih besar daripada tekanan udara didalam rongga dada. Akhirnya udara naik dari lambung (rongga perut) menuju ke esophagus (kerongkongan). Pada saat itu laring tertutup agar udara dari lambung tidak masuk ke paruparu, sementara katup kerongkongan atas dan bawah terbuka sehingga memudahkan udara keluar lewat kerongkonan menuju mulut untuk dilepaskan. ${ }^{15}$

\section{Gambaran klinis perut kembung}

Dari hasil penelitian gambaran klinis penderita dispepsia keluhan utama terbanyak yang dikeluhkan pasien datang kerumah sakit adalah perut kembung, dengan total sebanyak 75 responden $(78,9 \%)$. Hal ini sesuai dengan penelitian yang dilakukan oleh Arnelis tahun 2016 yaitu ada 50 responden $(92,59 \%)$ dari 54 responden yang mengalami keluhan perut kembung.

Pada saat kembung perut biasanya terasa penuh, kencang dan bergas. Perut bergas diakibatkan karena udara yang ikut masuk beserta dengan makanan yang dimakan, sifat kembung bisa berkelanjutan atau hilang timbul. ${ }^{4}$

\section{Kombinasi gejala penderita dispepsia}

Dari hasil penelitian gambaran klinis penderita dispepsia yang datang ke rumah sakit didapatkan bahwa paling banyak ditemukan pasien datang dengan 3 keluhan yaitu sebanyak 35 responden $(36,84 \%)$ dimana keluhan yang paling sering yaitu cepat kenyang, sendawa dan kembung. Pasien yang datang dengan 4 keluhan yaitu sebanyak 25 responden $(26,31 \%)$ dimana keluhan yang paling sering yaitu mual, cepat kenyang, sendawa, dan kembung. Pasien yang datang dengan 5 keluhan ada sebanyak 17 responden $(17,89 \%)$ yaitu mual, muntah, cepat kenyang, sendawa, dan kembung. Pasien yang 
MEDIKA ALKHAIRAAT : JURNAL PENELITIAN KEDOKTERAN DAN KESEHATAN 1(2): 57-63

datang dengan 2 keluhan yaitu sebanyak 13 responden $(13,70 \%)$ dimana keluhan yang paling sering dikeluhakan yaitu cepat kenyang, dan kembung. Dari hasil tersebut ditemukan bahwa keluhan yang paling sering muncul yaitu cepat kenyang dan kembung. Hal ini sejalan dengan penelitian yang dilakukan oleh Rizky tahun 2015 yaitu dari 77 responden ada 38 orang $(49,4 \%)$ yang mengalami keluhan cepat kenyang dan menurut Arnelis tahun 2016 yaitu ada 50 responden $(92,59 \%)$ dari 54 responden yang mengalami keluhan perut kembung.

\section{DAFTAR PUSTAKA}

1. Bonner GF. 2006. Upper gastrointestinal evaluation related to the pelvic floor. In: Davila GW. Ghoniem GM, Wexner SD, editors. Pelvic Floor Dysfunction. 1st ed. Springer-Verlag London Limited

2. Talley $\mathrm{Nj}$, Colin-Jones $\mathrm{D}$, Koch KL, Koch M, Nyren O, Stanghellini V.2004. Functional dyspepsia: a classification with guidelines for diagnosis and management. Gastroenterol Int

3. Talley NJ, Stanghellini V, Heading RC, Koch KL, Malagelada JR, Tytgat GN. 2006. Functional gastroduodenal disorders. Gastroenterology.

4. Anonim. 2010. Appendix B: Roma III Diagnostic criteria for functional gastrointestinal disorders. Am J Gastroenterol.

5. Khademolhosseini F, et al. 2010. Prevalence of dyspepsia and ist correlation with demographic factors and lifestyle in shiraz, Southem Iran. Middle East Journal of Digestive Disease.

6. Ababaw, W., Kibret, M., Abera, B. 2015. Prevalence and Risk Factors of H.pylori from Dyspeptic Patients in Northwest Ethiopia. Asian Pac J Cancer Prev

7. Ihezue $\mathrm{CH}$, Oluwole FS, Onuminya JE, Okoronkwo MO. 2012. Dyspepsia among the highlanders of Nigeria: an epidemiological survey. Afr J Med Sci.
8. WHO. Emergency and Humanitarian Action (EHA), WHO Indonesia. 2010. Emergency situation report Mt. Merapi volcano eruption, Central Java Province, Republic of Indonesia

9. Profil Kesehatan Provinsi Solo. 2008. Departemen Kesehatan Provinsi Solo.

10. Depkes RI. Profil Kesehatan Indonesia. 2008. Jakarta: Departemen Kesehatan Republik Indonesia.

11. Djojodiningrat D, Dispepsia fungsional. In: Sudoyo AW, Setyohadi B, Alwi I, Simadibrata M, Setiati S, editors. 2014. Buku Ajar Ilmu Penyakit Dalam. Edisi ke-6. Jakarta.

12. Feldman M. 2016. Nausea and vomiting. In: Sleisenger MH, Fordtran JS, eds. Gastrointestinal disease. Philadelphia: W. B. Saunders

13. Maule W. 2014. Nausea and Vomiting. NCBI

14. Baker, G. Fraser, R.J., Young, G. 2006. Subtypes of functional dyspepsia. World J Gastroenterol

15. Bestene, J.A, 2010. Visceral sensitivity and functional dyspepsia. Asociaciones Colombianas de Gastroenterologia, Endoscopia digestiva, Coloproctologia Hepatologia 